\title{
EPITAXIAL GROWTH OF GARNETS FOR THIN FILM LASERS
}

\author{
D. PELENC, B. CHAMBAZ, I. CHARTIER, B. FERRAND and J.C. VIAL* \\ LETI/DOPT-CEA-CENG 85X, F-38401 Grenoble cedex, France \\ *Laboratoire de Spectrométrie Physique, Université Joseph Fourier Grenoble, BP. 87, \\ F-38042 Saint-Martin d'Hères cedex, France
}

Abstract: Liquid Phase Epitaxy of YAG:Nd waveguides is presented. Epitaxial material is compared to Czockralski grown YAG:Nd. First laser results are given, including guided emission in a multimode layer.

\section{Introduction.}

Miniature lasers are the object of considerable research in optoelectronics. Among them, waveguide lasers hold out the advantage of low pump threshold (1). A planar waveguide laser consists of a thin film of laser material on a substrate of lower refractive index. We have realised such a structure by Liquid Phase Epitaxy (LPE) of YAG:Nd monocristalline films on pure YAG substrates and observed laser emission in transversal and longitudinal configurations. Furthermore, YAG:Nd epitaxial layers reach much higher Nd concentration than bulk crystals.

\section{Liquid Phase Epitaxy.}

The growing technique takes advantage of the property of $\mathrm{PbO}-\mathrm{B}_{2} \mathrm{O}_{3}$ solutions to stand supersaturated without spontaneous nucleation occuring. Solutions of $\mathrm{PbO} / \mathrm{B}_{2} \mathrm{O}_{3} / \mathrm{Al}_{2} \mathrm{O}_{3} / \mathrm{Y}_{2} \mathrm{O}_{3} / \mathrm{Nd}_{2} \mathrm{O}_{3}$ in respectively $90 / 7.5 / 1.9 / 0.49 / 0.11$ typical atomic concentrations were kept several degrees under their saturation temperature in a two zones furnace designed to minimize the axial thermal gradient. Pure YAG (111) oriented substrates were dipped horizontally into the melt for several minutes with alternate rotation. Growth occured on both sides of the substrate, at a typical rate of $1 \mu \mathrm{m} / \mathrm{mn}$, depending on the supercooling. More details on growth conditions can be found in (2).

YAG:Nd layers 5 to $160 \mu \mathrm{m}$ thick were realised (table I). Depending on the melt, Nd concentration (measured by X-ray microprobe analysis) can reach $15 \%$, whereas maximum concentration of Czockralski grown YAG:Nd is about $1 \%$. Optical quality is fairly good but decreases for thicker layers or at higher growth rates. Lattice mismatch $\Delta \mathrm{a}$ increases linearly with $\mathrm{Nd}$ concentration. Lutetium substitution is studied, in order to minimize $\Delta \mathrm{a}$. 
Table I: Typical layers obtained by LPE.

\begin{tabular}{|c|c|c|c|c|c|c|c|c|c|}
\hline $\begin{array}{c}(\mathrm{Nd} / \mathrm{Y}+\mathrm{Nd})_{\text {melt }} \\
(\%)\end{array}$ & 2,7 & 18,1 & 18,1 & 18,1 & 18,1 & 25 & 25 & 25 & 40 \\
\hline $\begin{array}{c}\text { Thickness } \\
(\mu \mathrm{m})\end{array}$ & 8,7 & 5,3 & 34 & 100 & 160 & 9,2 & 11 & 80 & 7,7 \\
\hline $\begin{array}{c}(\mathrm{Nd} / \mathrm{Y}+\mathrm{Nd})_{\text {film }} \\
\text { from X analysis } \\
(\%)\end{array}$ & 0,7 & & & & & 4,5 & 5,5 & & 15 \\
\hline $\begin{array}{c}\Delta \mathrm{a} \\
\left(\mathrm{a}_{\text {subst.- }} \mathrm{a}_{\mathrm{film}} \mid\right. \\
\left(10^{-4} \mathrm{n} \mathrm{m}\right)\end{array}$ & 0,45 & 1,1 & 5,1 & 2,1 & 1,6 & 7,8 & 8,9 & 8,8 & 29 \\
\hline $\begin{array}{c}(\mathrm{Nd} / \mathrm{Y}+\mathrm{Nd})_{\text {film }} \\
\text { from } \Delta \mathrm{a} \\
(\%)\end{array}$ & 0,7 & 1,5 & 3,6 & 1,9 & 1,7 & 4,6 & 5,1 & 5 & 15 \\
\hline
\end{tabular}

3. Comparison between bulk and epitaxial material.

3.1. Spectral linewidth:

Comparison between the absorption linewidth around $590 \mathrm{~nm}$ confirms the epitaxial material quality even at high concentration (fig.1). Measurements on low concentrated layers lead to the same conclusion.

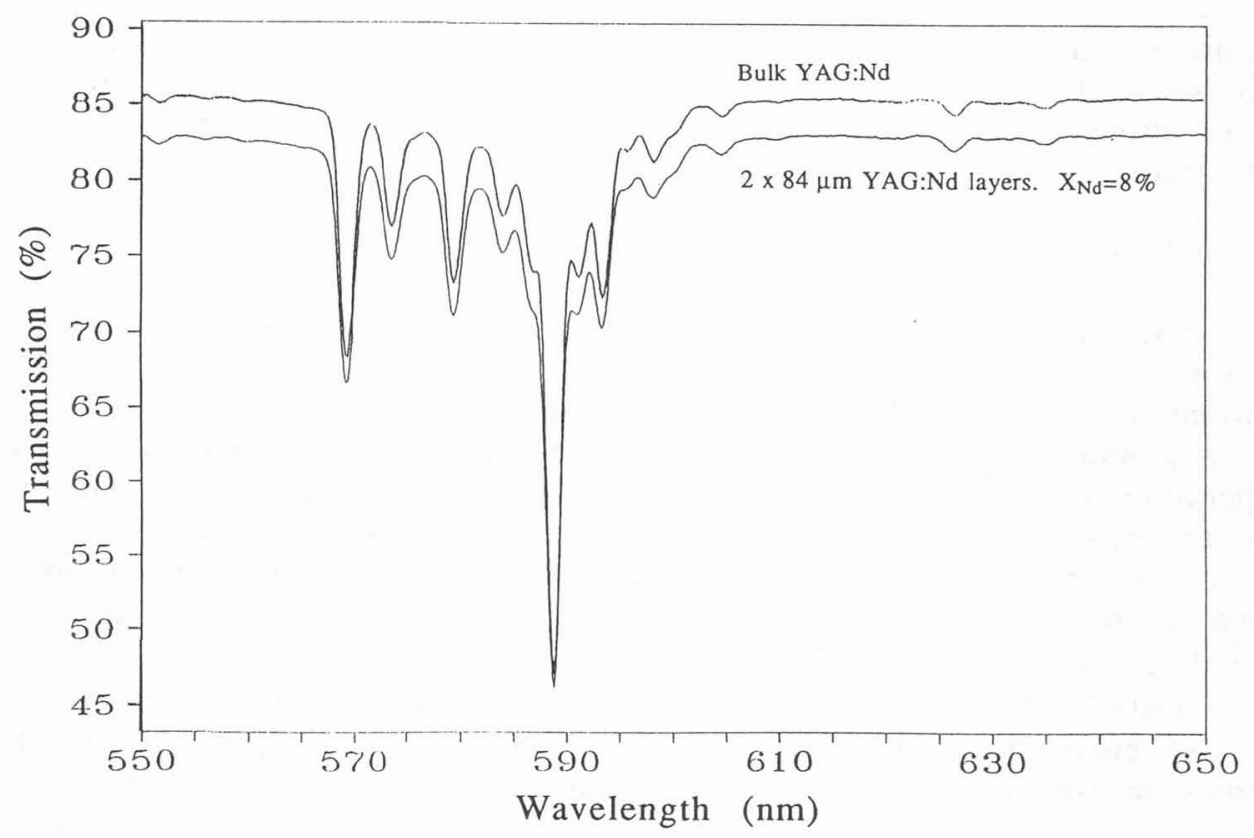

Fig. 1 Transmission spectra of bulk YAG:Nd and YAG:Nd epitaxial layers. 
3.2. Luminescence lifetime:

Luminescence lifetime measurements have been performed with a $514.5 \mathrm{~nm}$ pump beam and are compared to bulk YAG:Nd on figure 2 . Both behaviours are identical in the range $0-6 \%$, the variation of $\mathrm{Kc}\left(\propto \mathrm{C}^{2}\right)$ being characteristic of the strong quenching existing in YAG:Nd (3).

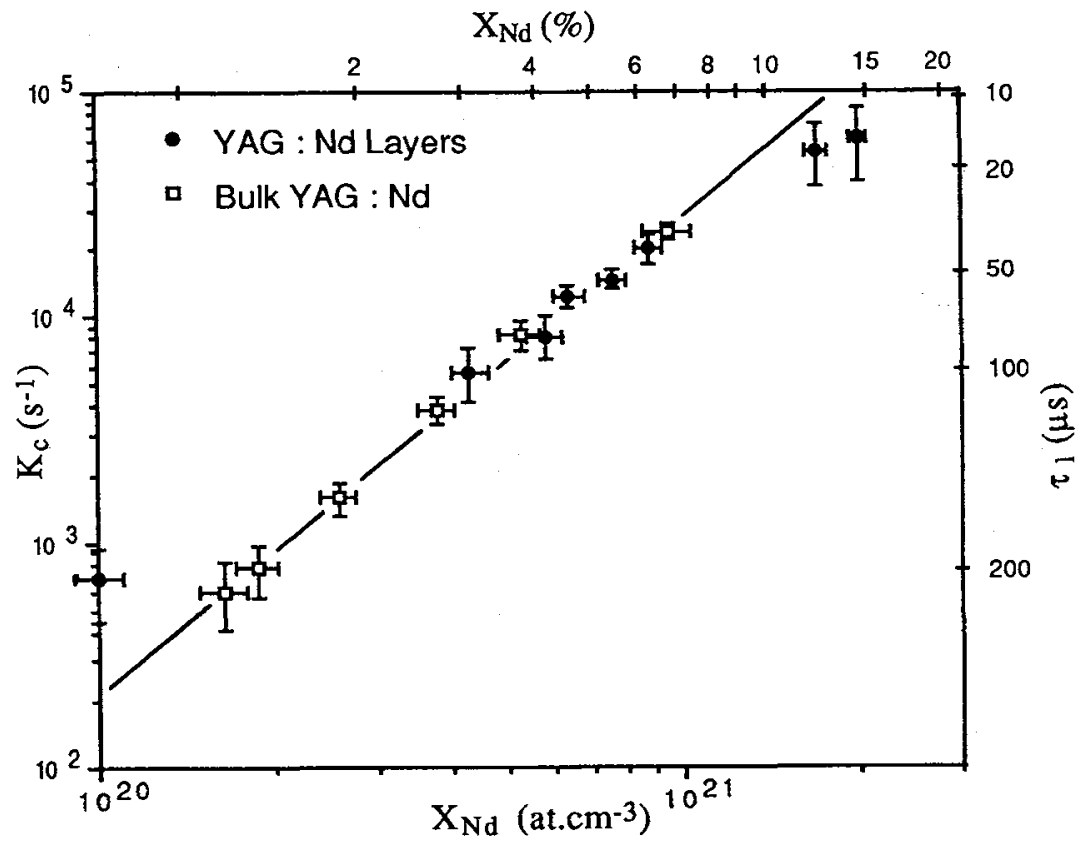

Fig. 2 Quenching rate $\mathrm{K}_{\mathrm{c}}$ versus $\mathrm{Nd}$ concentration for bulk YAG:Nd and YAG:Nd epitaxial layers.

$\mathrm{K}_{\mathrm{c}}=1 / \tau_{\mathrm{l}}-1 / \tau_{\mathrm{r}}$

$\tau_{1}:$ luminescence lifetime

$\tau_{\mathrm{r}}$ : radiative lifetime $\left(240 \mu \mathrm{s}\right.$ for $\mathrm{Nd}^{3+}$ in $\left.\mathrm{YAG}\right)$.

4. Laser tests.

4.1. Transversal configuration:

We have performed transversal pumping laser tests in the planoconcave cavity represented in figure 3 . Absorbed threshold are $30 \mathrm{~mW}$ and 85 $\mathrm{mW}$ and slope efficiencies are about $0.15 \%$ and $5 \%$ for two output mirrors, Rmax and $\mathrm{T}=2 \%$ respectively. Thresholds are comparable to those obtained by $\mathrm{D}$. Hanna in Southampton University on previous layers grown at the LETI.

\subsection{Longitudinal configuration:}

Owing to the increase of refractive index due to the substitution of Nd, the YAG:Nd layer can act as a waveguide. Pump guiding offers the advantage of a better overlap between pump and emitted modes, and therefore lower thresholds and higher slope efficiencies can be expected. 
For simplicity, first laser trials were realised on a multimode waveguide layer $120 \mu \mathrm{m}$ thick, $2 \%$ concentrated, with around $15 \mathrm{TE}$ guided modes. The experimental setup was identical to that of figure 3, except that the sample, a $5 \times 5 \mathrm{~mm}^{2}$ piece optically polished on two opposite sides, was $90^{\circ}$ tilted to be end -pumped.

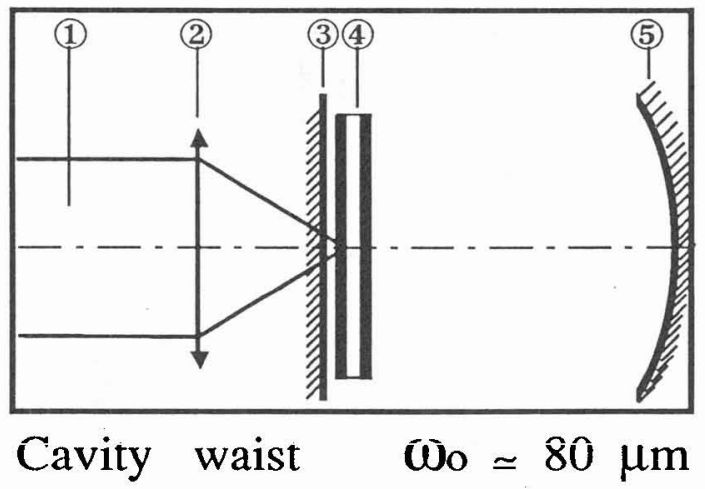

(1) Pump beam $\mathrm{P}_{\max }=500 \mathrm{~mW} \lambda=590 \mathrm{~nm}$

(2) Focusing lens $\mathrm{f}=40 \mathrm{~mm}$

(3) Flat mirror $\mathrm{R}_{\max }$ at $1.06 \mu \mathrm{m}$

(4) Sample : $2 \times 80 \mu \mathrm{m}$ YAG : Nd layers $\mathrm{X}_{\mathrm{Nd}}=7 \%$

(5) Concave output mirror Pump waist $\omega_{\mathrm{p}} \simeq 28 \mu \mathrm{m}$

Fig 3 Cavity for laser tests in transversal pumping configuration

Laser effect has been observed with an R-max coated output mirror. Threshold and slope efficiency measurements are in progress.

In order to obtain small size laser, multidielectric layers will be deposited on each side of the sample. Diode pumping will also be studied to realize a monolithic device.

Acknowledgements:

The authors would like to thank G. Rolland and F.Laugier for the $\Delta$ a measurements, S. Marthon and F. Pierre for the composition analysis and R. Romero and A. Chabli for their help in laser tests.

References:

1 Möckel-Plättner; Siemens Forsch-u.Entwickl - Bd 5 (1976) Nr 5, pp 296301.

2 B. Ferrand, B. Chambaz, D. Pelenc, Ch. Wyon. ECCG -3 Budapest. 5-11 May 1991.

3 A.A. Kaminskii. Laser Crystals. Ed Springer-Verlag. 